\title{
Extração de fósforo em solos cultivados com cana-de-açúcar e suas relações com a capacidade tampão
}

\author{
Djalma E. Simões Neto ${ }^{1}$, Alexandre C. de O liveira ${ }^{1}$, Fernando J. Freire ${ }^{2}$, \\ Maria B. G. dos S. Freire ${ }^{2}$, Clístenes W. A. do Nascimento ${ }^{2} \&$ Alexandre T. da Rocha ${ }^{3}$
}

\begin{abstract}
RESUMO
Apesar da preocupação com a produtividade esperada, a recomendação de adubação fosfatada para o Estado de Pernambuco é omissa quanto à influência da capacidade tampão dos solos na disponibilidade de P. 0 bjetivou-se, então, neste trabalho, avaliar métodos de extração para estimativa do P disponível considerando-se o teor e a qualidade da fração argila, além das características mineralógicas, químicas e físicas dos solos. O s experimentos foram conduzidos em condições de campo, na Zona da Mata de Pernambuco, em cinco solos: Argissolo Amarelo distrocoeso (PAdx); Latossolo Amarelo distrófico (LAd); Argissolo Amarelo distrófico (PAd); Gleissolo háplico eutrófico (GXve) e Espodossolo cárbico duripânico (EKo). Os tratamentos consistiram em sete doses de $P$, determinadas em função da capacidade máxima de adsorção de P (CMAP). 0 delineamento experimental foi em blocos ao acaso, com quatro repetições. Nas amostras de solo coletadas após a aplicação dos tratamentos, determinou-se o teor de P pelos extratores Mehlich-1, Mehlich-3, Bray-1 e Resina de Troca lônica (RTI). A RTI não apresentou correlação com características químicas ou físicas dos solos, tendo extraído P indistintamente, independente do solo; no entanto, M ehlich-1 mostrou-se altamente sensível à capacidade tampão de $\mathrm{P}$ do solo.
\end{abstract}

Palavras-chave: extratores de $P$, capacidade tampão de $P$, adsorção de $P$

\section{Extraction of phosphorus in soils cultivated with sugarcane and relationship with buffer capacity of the soil}

\begin{abstract}
Despite concerns with expected production, the phosphate fertilizer recommendations for Pernambuco do not take into account influence of the buffer capacity of soil on P availability. Therefore, this work had as objective to evaluate extraction methods to estimate $P$ availability considering content and quality of clay fraction as well mineralogical, chemical and physical soil characteristics. The experiments were carried under field conditions at 'Zona da M ata' of sugarcane cropping area of the State. Five soils were used: Argisol Yellow distrocoeso (PAdx); Latosol Yellow distrophic (LAD); Argisol Yellow distrofic (PAd); Gleisol haplic eutrophic (GXVe); and Espodosol carbic duric (ESKo). The treatments consisted of seven doses of $P$, determined in function of the $P$ maximum capacity of adsorption (PMCA). The experimental design was a completely randomized treatment block, with four replications. In soil samples collected after treatment application, P was determined by Mehlich-1, Mehlich-3, Bray-1 and ion-exchange resin extractors. lon-exchange resin did not present correlation with any physical or chemical characteristics of the soils, having extracted P indistinctly, and independent of the soil. However, Mehlich1 was highly sensible to buffer capacity of $P$ in soil.
\end{abstract}

Key words: extractors of $P$, buffer capacity of $P, P$ adsorption

\footnotetext{
${ }^{1}$ U FRPE/Estação Experimental de Cana-de-açúcar do Carpina, Rua Ângela Cristina de Luna, Bairro Novo, CP 40, CEP 55.819-225, Carpina, PE. Fone (81) 3622 0444; Fax (81) 3622-0244. E-mail:desn@oi.com.br

2 Departamento de Agronomia/U FRPE, Rua Dom Manoel de Medeiros, Campus U niversitário de Dois Irmãos, 52171-900, Recife, PE. Fone (81) 3320-6223, Fax (81) 3320 6220. E-mail: f.freire@depa.ufrpe.br

3 UFRPE/U nidade Acadêmica de Serra Talhada, Fazenda Saco, s/n, CP 063, CEP 56900-000, Serra Talhada, PE. Fone: (87) 3831-1927. E-mail: alexandre@nast.ufrpe.br
} 


\section{INTRODUÇÃO}

A cana-de-açúcar cultivada no Brasil teve, na safra 2006/ 2007, expressivo crescimento no mercado mundial, cenário liderado pelo País, com produção de 514.079 .729 t em 7.822 .342 ha e produtividade de 76,594 $\mathrm{t} \mathrm{ha}^{-1}$. Ressalta-se que, no Nordeste, foram produzidas $67.844 .327 \mathrm{t}$ em 1.230.061 ha, suplantado apenas pelo Sudeste, com 345.627.058 t em 5.219.368 ha. O Estado de São Paulo é o primeiro produtor nacional de canade-açúcar, com 295.477.005 t em 4.328.450 ha cultivados, enquanto Pernambuco participa com $18.866 .525 \mathrm{t}$ em $369.683 \mathrm{ha}$ colhidos, ocupando o quinto lugar no ranking (IBGE, 2007).

O P é um elemento importante para a cultura da cana-deaçúcar, em virtude de participar, direta e indiretamente, de diversos processos metabólicos; atua no desenvolvimento das raízes, aumenta a produção de colmos e atua nas características industriais, como porcentagem aparente de sacarose contida no caldo da cana (pol\%), pureza de caldo e clarificação; sua deficiência pode levar à diminuição na formação de sacarose. Em relação a outros macronutrientes, é requerido em menor quantidade pela planta, porém as adubações são elevadas, pelas características apresentadas por diferentes tipos de solo, que fazem com que a maior parte do $\mathrm{P}$ adicionado se torne indisponível à planta (Bastos et al., 2008).

De acordo com Corrêa et al. (2005), o teor e o tipo de argila, a capacidade de troca de cátions (CTC), o poder tampão, a adsorção de $\mathrm{Ca}$ e de $\mathrm{P}$, o teor de matéria orgânica e a umidade, afetam a solubilização de P no solo e, consequentemente, sua extração. Segundo alguns autores (Rolim Neto et al., 2004; Silva et al., 2004; Rocha et al., 2005) o aumento do poder tampão de fosfato do solo diminui a extração de P do solo pelos extratores constatando-se que, em solo com menor teor de argila, elevado valor de $\mathrm{P}$ remanescente (P-rem) e baixa CMAP, as extrações de P são maiores.

Em Pernambuco o método utilizado para extração do P disponível é o Mehlich-1 (IPA, 1998), porém não considera que esse extrator é sensível à capacidade tampão de fosfato do solo e que seus níveis críticos variam com essa característica; assim, a recomendação de adubação fosfatada para canade-açúcar no Estado de Pernambuco pode estar sendo superestimada em solos arenosos ou subestimada em solos argilosos; portanto, tornam-se imprescindíveis pesquisas que fundamentem a utilização desse extrator, comparativamente a outros métodos utilizados no Brasil.

As recomendações de adubação fosfatada devem considerar características do solo que reflitam o fator capacidade de $\mathrm{P}(\mathrm{FCF})$, uma vez que elas determinam a variação entre os solos quanto à capacidade de adsorver $\mathrm{P}$; desta forma, isotermas de adsorção são ajustadas e, por meio delas, pode-se estimar as quantidades de $\mathrm{P}$ que devem ser aplicadas ao solo (Corrêa et al., 2008), para que quantidades adequadas deste elemento possam estar disponíveis para absorção.

No Brasil, praticamente apenas dois métodos de extração de P são utilizados: o Mehlich-1, com utilização mais universalizada em todo o País, e o P-resina, utilizado nos Estados de São Paulo e Paraná. A grande vantagem do Mehlich-1 é a simplicidade de extração; no entanto, Raij et al. (2001) ressaltam que a vantagem é apenas operacional. Os autores salien- tam que o método da Resina é um procedimento com embasamento teórico mais consistente e que a Resina tem propriedades que permitem a avaliação apenas do P lábil, ou seja, é um material sintético, orgânico, poroso, com estrutura que contém grupos químicos com cargas positivas, que adsorvem os ânions $\mathrm{H}_{2} \mathrm{PO}_{4}^{-}$da solução aquosa em contato com o solo.

Em revisão realizada por Silva \& Raij (1999), os autores constataram que o método da Resina apresenta aspectos favoráveis, tais como: elevados valores de coeficientes de determinação para a correlação entre $\mathrm{P}$ absorvido pela planta $\mathrm{e}$ $\mathrm{P}$ extraído do solo; pode ser usado tanto em solos ácidos como alcalinos; revela, adequadamente, o efeito da calagem em aumentar a disponibilidade de P; não superestima a disponibilidade de $\mathrm{P}$ em solos tratados com fosfatos naturais $\mathrm{e}$ é o que apresenta o melhor embasamento teórico para a determinação do chamado "fator quantidade" de P nos solos porém o método Mehlich-1 é utilizado na maioria dos laboratórios de análises de solo da região Nordeste do Brasil para determinação do P disponível, conforme recomenda o Programa de Análise de Qualidade de Laboratórios de Fertilidade da Embrapa Solos (PAQLF) (Silva et al., 2004). É um extrator ácido que tem a vantagem de possibilitar extratos límpidos e facilidade de execução de análise devido à maior velocidade de decantação das suspensões com baixo $\mathrm{pH}$, dispensando filtração, mas apresentando baixa extração de P em Latossolos com textura argilosa e com teores elevados de óxidos de Fe e Al (Silveira et al., 2006), assim se objetivou neste trabalho, avaliar métodos de extração para estimativa do P disponível considerando-se características químicas, físicas e mineralógicas dos solos.

\section{MATERIAL E MÉTODOS}

Os experimentos foram conduzidos em condições de campo na Zona da Mata do Estado de Pernambuco, em áreas de empresas do setor sucroalcooleiro e da Estação Experimental de Cana-de-açúcar de Carpina (EECAC) da UFRPE, onde predominam solos muito intemperizados de diferentes características químicas, físicas e mineralógicas (Tabela 1); nessas áreas, as características edafoclimáticas são distintas, conforme detalhadas por Koffler et al. (1986), que caracterizaram a Zona da Mata em cinco regiões edafoclimáticas: Norte, Litoral Norte, Centro, Sul e Litoral Sul.

Selecionadas as cinco áreas para instalação dos experimentos de campo, retiraram-se amostras dos solos na profundidade de 0,0-0,2 m; em seguida, foram secadas ao ar e passa-

Tabela 1. Identificação dos solos e localização dos experimentos de campo

\begin{tabular}{lcc}
\hline \multicolumn{1}{c}{ Identificação/classe } & Localização & Municípios \\
PAdx - Argissolo Amarelo Distrocoeso & EECAC & Carpina/PE \\
LAd - Latossolo Amarelo Distrófico & Usina Cucau & Rio Formoso/PE \\
PAd - Argissolo Amarelo Distrófico & Usina Pumaty & J oaquim Nabuco/PE \\
GXve - Gleissolo Háplico Eutrófico & Usina Salgado & Ipojuca/PE \\
EKo - Espodossolo Humilúvico Órtico & Usina Santa Tereza & Goiana/PE \\
\hline
\end{tabular}


das em peneira de $2 \mathrm{~mm}$ de malha, procedendo-se à realização de análises físicas e químicas (Tabela 2).

Tabela 2. Características químicas e físicas dos solos das áreas experimentais

\begin{tabular}{|c|c|c|c|c|c|}
\hline Características & PAdx & LAd & PAd & GXve & EKo \\
\hline $\mathrm{pH}\left(\mathrm{H}_{2} \mathrm{O} 1: 2,5\right)$ & 5,20 & 4,10 & 4,80 & 4,90 & 5,55 \\
\hline $\mathrm{pH}(\mathrm{KCl} 1: 2,5)$ & 4,00 & 3,60 & 3,80 & 3,60 & 4,40 \\
\hline $\left.\mathrm{H}^{+}+\mathrm{Al}^{3+}(\mathrm{cmol} \mathrm{dm})^{-3}\right)$ & 5,20 & 9,24 & 7,00 & 6,77 & 3,22 \\
\hline $\mathrm{Al}^{3+}\left(\mathrm{cmol} \mathrm{dm}^{-3}\right)$ & 0,35 & 2,00 & 1,00 & 1,20 & 0,00 \\
\hline $\mathrm{Ca}^{2+}\left(\mathrm{cmol}_{\mathrm{c}} \mathrm{dm}^{-3}\right)$ & 1,90 & 0,20 & 0,90 & 5,80 & 2,20 \\
\hline $\mathrm{Mg}^{2+}\left(\mathrm{cmol}_{\mathrm{c}} \mathrm{dm}^{-3}\right)$ & 0,50 & 0,20 & 0,50 & 2,20 & 0,50 \\
\hline $\mathrm{Na}^{+}\left(\mathrm{cmol}_{\mathrm{c}} \mathrm{dm}^{-3}\right)$ & 0,01 & 0,02 & 0,03 & 0,19 & 0,04 \\
\hline $\mathrm{K}^{+}\left(\mathrm{cmol}_{\mathrm{c}} \mathrm{dm}^{-3}\right)$ & 0,07 & 0,11 & 0,10 & 0,21 & 0,07 \\
\hline P-Mehlich ${ }^{-1}\left(\mathrm{mg} \mathrm{dm}^{-3}\right)$ & 2,83 & 0,02 & 0,70 & 4,18 & 2,17 \\
\hline $\operatorname{CMAP}\left(\mathrm{mg} \mathrm{cm}^{-3}\right)^{1}$ & 0,33 & 0,67 & 0,78 & 0,82 & 0,10 \\
\hline P-rem $\left(\mathrm{mg} \mathrm{L}^{-1}\right)^{2}$ & 41,00 & 12,00 & 17,00 & 17,00 & 46,00 \\
\hline $\mathrm{m}(\%)$ & 12,36 & 79,03 & 39,46 & 12,50 & 0,00 \\
\hline$V(\%)$ & 32,29 & 5,43 & 17,98 & 55,40 & 46,69 \\
\hline PST (\%) & 0,45 & 0,94 & 1,29 & 1,95 & 1,55 \\
\hline CTCefetiva $\left(\mathrm{cmol}_{\mathrm{c}} \mathrm{dm}^{-3}\right)$ & 2,83 & 2,52 & 2,53 & 9,60 & 2,81 \\
\hline CTCtotal $\left(\mathrm{cmol}_{\mathrm{c}} \mathrm{dm}^{-3}\right)$ & 7,68 & 9,76 & 8,53 & 15,17 & 6,03 \\
\hline $\mathrm{Cu}\left(\mathrm{mg} \mathrm{dm}^{-3}\right)$ & 1,05 & 0,85 & 0,35 & 2,40 & 0,60 \\
\hline $\mathrm{Fe}\left(\mathrm{mg} \mathrm{dm}^{-3}\right)$ & 76,401 & 140,30 & 190,15 & 215,00 & 52,40 \\
\hline $\mathrm{Zn}\left(\mathrm{mg} \mathrm{dm}^{-3}\right)$ & 1,50 & 1,30 & 0,85 & 3,85 & 1,35 \\
\hline $\mathrm{Mn}\left(\mathrm{mg} \mathrm{dm}^{-3}\right)$ & 6,20 & 1,12 & 1,15 & 52,00 & 5,60 \\
\hline$C\left(g_{k g}^{-1}\right)$ & 8,90 & 9,60 & 17,90 & 13,80 & 10,70 \\
\hline Areia $\left(\mathrm{g} \mathrm{kg}^{-1}\right)$ & 785,8 & 311,6 & 539,20 & 51,60 & 855,80 \\
\hline Silte $\left(\mathrm{g} \mathrm{kg}^{-1}\right)$ & 54,6 & 9,2 & 9,20 & 209,20 & 64,60 \\
\hline Argila $\left(\mathrm{g} \mathrm{kg}^{-1}\right)$ & 159,6 & 679,2 & 451,60 & 739,20 & 79,60 \\
\hline Densidade do solo $\left(\mathrm{kg} \mathrm{dm}^{-3}\right)$ & 1,41 & 1,13 & 1,05 & 1,02 & 1,50 \\
\hline Densidade das partículas $\left(\mathrm{kg} \mathrm{dm}^{-3}\right)$ & 2,67 & 2,63 & 2,67 & 2,56 & 2,63 \\
\hline$C C\left(g^{-1}\right)^{3}$ & 0,09 & 0,35 & 0,25 & 0,66 & 0,06 \\
\hline PMP $\left(g g^{-1}\right)^{4}$ & 0,05 & 0,19 & 0,17 & 0,21 & 0,02 \\
\hline $\mathrm{k}\left(\mathrm{cm} \mathrm{h} \mathrm{h}^{-1}\right)^{5}$ & 11,60 & 6,32 & 20,92 & 1,12 & 23,05 \\
\hline
\end{tabular}

${ }^{1}$ Capacidade máxima de adsorção de fósforo; ${ }^{2}$ Fósforo remanescente; ${ }^{3}$ Capacidade de campo; ${ }^{4}$ Ponto de murcha permanente; ${ }^{5}$ Condutividade hidráulica

Os solos foram caracterizados, fisicamente, pela sua granulometria, densidade do solo, densidade das partículas, capacidade de campo, ponto de murcha permanente e condutividade hidráulica saturada, segundo os métodos da EMBRAPA (1997); quimicamente, eles foram caracterizados pelo $\mathrm{pH}\left(\mathrm{H}_{2} \mathrm{O}\right) ; \mathrm{pH}(\mathrm{KCl}) ; \mathrm{Ca}^{2+} ; \mathrm{Mg}^{2+} ; \mathrm{Na}^{+} ; \mathrm{K}^{+} ; \mathrm{Al}^{3+} ;(\mathrm{H}+\mathrm{Al})$; P; C.; P-rem; CMAP; Cu, Fe, Zn e Mn. O Ca ${ }^{2+}, \mathrm{Mg}^{2+}$ e $\mathrm{Al}^{3+}$ foram extraídos por $\mathrm{KCl}$ 1,0 mol L-1; o $\mathrm{P}$ e o K por Mehlich-1 e o $(\mathrm{H}+\mathrm{Al})$ por acetato de cálcio $0,5 \mathrm{~mol} \mathrm{~L}{ }^{-1}$, conforme EMBRAPA (1997). O Ca ${ }^{2+}$ e o $\mathrm{Mg}^{2+}$ foram determinados por espectrofotometria de absorção atômica, o $\mathrm{K}^{+}$por fotometria de chama e o $\mathrm{P}$ por colorimetria, conforme Braga \& Defelipo (1974); o $\mathrm{Al}^{3+}$ e o $(\mathrm{H}+\mathrm{Al})$ por titulometria e o $\mathrm{C}$ por combustão úmida com dicromato de potássio.

O P-rem, que é a concentração de $\mathrm{P}$ da solução de equilíbrio após agitação durante $1 \mathrm{~h}$ da TFSA (terra fina secada ao ar) com solução de $\mathrm{CaCl}_{2} 10 \mathrm{mmol} \mathrm{L}^{-1}$, contendo $60 \mathrm{mg} \mathrm{L}^{-1}$ de P, na relação de 1:10, foi determinado de acordo com Alvarez et al. (2000).
Para a avaliação da CMAP as amostras de cada solo receberam doses de P baseadas no valor de P-rem (Alvarez \& Fonseca, 1990). Amostras de TFSA de cada solo foram saturadas com soluções de concentrações crescentes de $\mathrm{P}$ em $\mathrm{CaCl}_{2} 10 \mathrm{mmol} \mathrm{L}^{-1}$, adotando-se a isoterma de Langmuir para estimar a CMAP.

Realizaram-se a análise e a identificação mineralógica da fração argila dos solos por difratometria de raios-X (Whitting \& Allardice, 1986) (Figura 1), determinando-se os minerais predominantes (Tabela 3). Determinaram-se Fe amorfo e cristalino, extraídos por oxalato ácido de amônio (Feo) e ditionito - citrato - bicarbonato de sódio (Fed), respectivamente (Mehra \& Jackson, 1960; Schwertmann, 1964) e dosados por espectrofotometria de absorção atômica (Tabela 3).

Tabela 3. Identificação dos minerais predominantes nos solos, ferro amorfo (Feo) e cristalino (Fed) e suas relações (Feo/Fed)

\begin{tabular}{llccc}
\hline Solo & Mineral & Feo ${\mathbf{~ ( ~} \mathbf{~ k g}^{-1}}^{\mathbf{1}}$ & Fed ${\left.\mathbf{~ ( ~} \mathbf{~ k g}^{-1}\right)}^{\mathbf{1}}$ & Feo/Fed \\
EKo & Ct, Qz, Gt & 0,38 & 1,14 & 0,33 \\
GXve & Mi, Ct, Qz, Gb & 1,47 & 2,27 & 0,65 \\
PAd & Ct, Qz, Gt, Gb & 2,03 & 15,51 & 0,13 \\
LAd & Ct, Qz, Gt, Gb & 1,63 & 15,04 & 0,11 \\
PAdx & Ct, Qz, Gt & 0,54 & 1,39 & 0,39 \\
\hline
\end{tabular}

Ct-caulinita; Gb-gibsita; Gt-goethita; Qz-quartzo; Mi-mica; Ha-halita

Os tratamentos consistiram em sete níveis de $\mathrm{P}$ determinados em função da CMAP (Tabela 4). O delineamento experimental foi em blocos ao acaso, com quatro repetições, totalizando vinte e oito parcelas experimentais; cada parcela foi constituída de sete linhas com dez metros de comprimento utilizando-se, como espaçamento, $1 \mathrm{~m}$ entre linhas; as doses de $\mathrm{P}$ foram aplicadas no sulco de plantio e tiveram como fonte, superfosfato triplo.

Tabela 4. Níveis de $P$ em função da capacidade máxima de absorção de fósforo (CMAP) e doses correspondentes de fósforo

\begin{tabular}{crrrrr}
\hline Níveis P (\% da CMAP) & PAdx & LAd & $\begin{array}{c}\text { PAd } \\
\left(\mathbf{P}, \mathbf{~ k g ~ h a}^{-1}\right)\end{array}$ & GXve & EKo \\
0 & 0,0 & 0,0 & 0,0 & 0,0 & 0,0 \\
2 & 13,2 & 25,4 & 30,0 & 32,8 & 4,0 \\
4 & 26,4 & 51,1 & 60,2 & 65,6 & 8,0 \\
8 & 52,8 & 102,2 & 126,4 & 131,2 & 16,0 \\
12 & 79,2 & 153,3 & 189,6 & 196,8 & 24,0 \\
16 & 105,6 & 204,4 & 252,8 & 262,4 & 32,0 \\
20 & 132,0 & 255,5 & 316,0 & 328,0 & 40,0 \\
\hline
\end{tabular}

Três amostras simples foram coletadas em cada uma das três linhas centrais da área útil das parcelas, formando uma amostra composta por parcela; esta amostragem foi realizada 30 dias após o plantio e aplicação dos tratamentos, na profundidade de $0,0-0,2 \mathrm{~m}$ na linha da cana com uso de trado. Nessas amostras de solo coletadas se determinou o teor de $\mathrm{P}$ pelos extratores Mehlich-1 ( $\mathrm{HCl} \mathrm{0,05} \mathrm{mol} \mathrm{L-1}$ $+\mathrm{H}_{2} \mathrm{SO}_{4}$ 0,0125 mol L-1) (Mehlich, 1978); Mehlich-3 $\left(\mathrm{NH}_{4} \mathrm{~F} \quad 0,015 \mathrm{~mol} \mathrm{~L}^{-1}+\mathrm{CH}_{3} \mathrm{COOH} 0,2 \mathrm{~mol} \mathrm{~L} \mathrm{~L}^{-1}+\right.$ $\mathrm{NH}_{4} \mathrm{NO}_{3}$ 0,25 mol L-1 $\mathrm{HNO}_{3} 0,013 \mathrm{~mol} \mathrm{~L}^{-1}+$ EDTA $0,001 \mathrm{~mol} \mathrm{~L}^{-1}$ ) 


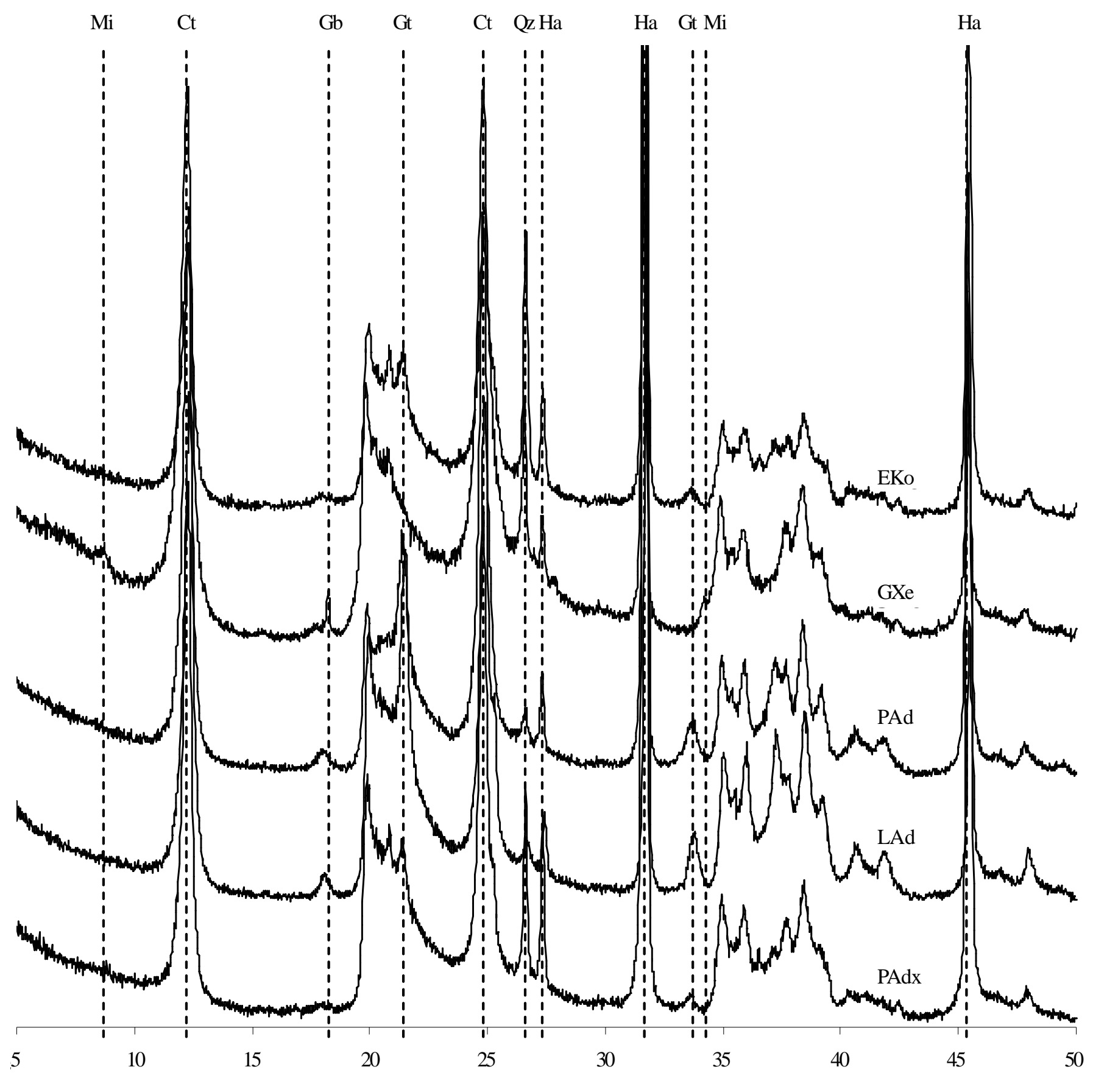

$\circ 2 \theta \mathrm{Cu} \mathrm{K \alpha}$

Ct-caulinita; Gb-gibbsita; Gt-goethita; Qz-quartzo; Mi-mica; Ha-halita

Figura 1. Difratogramas de raio-x da fração argila dos solos sem tratamento

(Mehlich, 1984); Bray-1 ( $\left.\mathrm{HCl} 0,025 \mathrm{~mol} \mathrm{~L}^{-1}+\mathrm{NH}_{4} \mathrm{~F} 0,03 \mathrm{~mol} \mathrm{~L}^{-1}\right)$ (Bray \& Kurtz, 1945) e Resina de Troca Iônica (RTI) (Raij et al., 1986).

Os dados das variáveis de solo foram submetidos a análise de variância, pelo teste $\mathrm{F}$ a $5 \%$ de probabilidade; em seguida, realizou-se análise de regressão para os efeitos significativos; testaram-se os coeficientes dos componentes de cada modelo escolhendo-se os modelos significativos, isto é, com maior coeficiente de determinação.
Correlações entre o teor de $\mathrm{P}$ extraído com características que refletem o poder tampão de fosfato dos solos foram estudadas, como argila, P-rem e CMAP.

\section{RESULTADOS E DISCUSSÃO}

O teor de P extraído nos solos por Bray-1, Mehlich-1, Mehlich-3 e RTI, mostrou variação na extração, verificando- 
se um aumento nos teores de P extraído em função das doses aplicadas (Tabela 5), porém este aumento não foi proporcional às doses mas atribuido às diferentes características químicas e físicas dos solos (Tabela 2) e às suas mineralogias (Figura 1 e Tabela 3) que influenciaram a CMAP.

A quantidade e a qualidade dos minerais de argila e, principalmente, a predominância de um mineral é, ainda, mais im-

Tabela 5. Teor de fósforo extraído dos solos pelos extratores Bray-1, Mehlich-1, Mehlich-3 e Resina de Troca lônica (RTI) em função do fósforo aplicado

\begin{tabular}{|c|c|c|c|c|c|}
\hline \multirow{2}{*}{ Solo* } & \multirow{2}{*}{$\begin{array}{l}\text { Doses P } \\
\left(\mathrm{kg} \mathrm{ha}^{-1}\right)\end{array}$} & Bray-1 & Mehlich-1 & Mehlich-3 & RTI \\
\hline & & \multicolumn{4}{|c|}{$\left(\mathrm{mg} \mathrm{dm}^{-3}\right)$} \\
\hline \multirow{8}{*}{ PAdx } & 0,0 & 7,39 & 4,91 & 2,52 & 10,0 \\
\hline & 13,2 & 7,73 & 4,97 & 2,70 & 14,3 \\
\hline & 26,4 & 10,55 & 7,62 & 4,11 & 34,5 \\
\hline & 52,8 & 18,93 & 13,08 & 6,82 & 51,3 \\
\hline & 79,2 & 20,46 & 13,89 & 7,12 & 44,5 \\
\hline & 105,6 & 24,25 & 16,31 & 7,45 & 53,3 \\
\hline & 132,0 & 22,09 & 16,53 & 7,88 & 71,0 \\
\hline & Média & 15,91 & 11,00 & 5,51 & 39,8 \\
\hline \multirow{8}{*}{ LAd } & 0,0 & 0,43 & 0,16 & 0,07 & 3,0 \\
\hline & 25,4 & 1,02 & 0,96 & 0,29 & 7,3 \\
\hline & 51,1 & 0,85 & 1,04 & 0,31 & 8,5 \\
\hline & 102,2 & 2,47 & 4,67 & 1,42 & 34,0 \\
\hline & 153,3 & 3,90 & 8,58 & 2,62 & 58,0 \\
\hline & 204,4 & 10,04 & 13,75 & 4,21 & 81,5 \\
\hline & 255,5 & 6,98 & 14,83 & 4,56 & 105,3 \\
\hline & Média & 3,67 & 6,28 & 1,93 & 42,5 \\
\hline \multirow{8}{*}{ PAd } & 0,0 & 0,53 & 0,49 & 0,09 & 5,3 \\
\hline & 30,0 & 2,19 & 2,11 & 0,24 & 19,5 \\
\hline & 60,2 & 5,52 & 5,14 & 0,65 & 51,3 \\
\hline & 126,4 & 7,46 & 6,66 & 0,94 & 65,8 \\
\hline & 189,6 & 25,87 & 19,56 & 5,44 & 231,0 \\
\hline & 252,8 & 44,46 & 19,91 & 9,97 & 197,0 \\
\hline & 316,0 & 33,53 & 23,55 & 7,04 & 305,3 \\
\hline & Média & 17,08 & 11,10 & 3,48 & 125,0 \\
\hline \multirow{8}{*}{ GXve } & 0,0 & 3,25 & 5,83 & 2,37 & 32,7 \\
\hline & 32,8 & 4,74 & 7,66 & 3,51 & 64,3 \\
\hline & 65,6 & 5,87 & 9,57 & 4,16 & 76,5 \\
\hline & 131,2 & 13,05 & 18,91 & 7,08 & 132,5 \\
\hline & 196,8 & 21,89 & 29,62 & 10,16 & 124,3 \\
\hline & 262,4 & 16,76 & 23,37 & 9,58 & 192,5 \\
\hline & 328,0 & 22,61 & 32,48 & 12,52 & 288,0 \\
\hline & Média & 12,60 & 18,21 & 7,05 & 130,1 \\
\hline \multirow{8}{*}{ EKo } & 0,0 & 1,69 & 2,15 & 0,96 & 8,3 \\
\hline & 4,0 & 3,26 & 3,46 & 1,37 & 14,0 \\
\hline & 8,0 & 2,46 & 3,70 & 1,41 & 12,0 \\
\hline & 16,0 & 8,34 & 13,51 & 4,48 & 73,5 \\
\hline & 24,0 & 6,08 & 12,68 & 5,15 & 92,0 \\
\hline & 32,0 & 6,37 & 14,13 & 3,48 & 75,0 \\
\hline & 40,0 & 10,91 & 13,05 & 5,72 & 92,0 \\
\hline & Média & 5,59 & 8,95 & 3,22 & 52,4 \\
\hline
\end{tabular}

PAdx - Argissolo Amarelo Distrocoeso; LAd - Latossolo Amarelo Distrófico; PAd - Argissolo Amarelo Distrófico; GXve - Gleissolo Háplico Eutrófico; EKo - Espodossolo Humilúvico Órtico portante. Almeida et al. (2003), estudando a cor do solo, formas de $\mathrm{P}$ e adsorção de fosfatos em Latossolos desenvolvidos de Basalto no Sul do Brasil, verificaram menor capacidade de sorção de $\mathrm{P}$ desses solos em razão da predominância da hematita em sua composição mineralógica.

Extratores químicos são utilizados para determinar quanto de $\mathrm{P}$ extraído do solo pode ser disponível às plantas; assim, teoricamente, esses extratores devem reproduzir o quanto de $\mathrm{P}$ a planta pode retirar do solo; no entanto, cada solo, dependendo das suas características químicas e físicas, responde diferentemente à ação dos extratores.

É oportuno, então, encontrar um extrator em que a quantidade de P extraída por ele se correlacione significativamente com as plantas e isto aconteça em diferentes tipos de solo sendo, também, de fácil manejo em laboratório de análises de rotina.

Nesta pesquisa o extrator que mais retirou $\mathrm{P}$ das amostras foi a RTI (Tabela 5), coerente com sua maior capacidade de extrair P de formas lábeis, independentemente do tamponamento do solo (Silva \& Raij, 1999).

Nos solos EKo, PAdx e LAd, a RTI extraiu menos P que em solos mais tamponados, como PAd e GXve, provavelmente pelo maior reservatório de P lábil desses solos (Tabela 2). Rossi \& Fagundes (1998), avaliaram a sensibilidade dos extratores Mehlich-1, Mehlich-2, Mehlich-3 e RTI em Latossolo Roxo, Argissolo Vermelho Amarelo e Latossolo Amarelo e concluíram que a RTI extraiu mais P; por outro lado, o Mehlich-1 extraiu mais $\mathrm{P}$ em solos menos tamponados, como o EKo e o PAdx, inclusive superando o P extraído nos solos LAd e PAd, ambos de elevada CMAP (Tabela 2), indicando uma provável sensibilidade do extrator à capacidade tampão de fosfato dos solos. No GXve, o Melhich-1 extraiu muito P, devido, sem dúvida, às elevadas doses de $\mathrm{P}$ utilizadas neste solo que pela maior capacidade de extração de $\mathrm{P}$ do extrator.

Apesar da simplicidade e rapidez em rotinas de análises de solo, os extratores ácidos apresentam baixa capacidade de extração de $\mathrm{P}$, como ocorreu com os Latossolos de textura argilosa e com teores elevados de óxidos de Fe e Al estudados na pesquisa desenvolvida por Silveira et al. (2006).

O Mehlich-3 foi o extrator que menos extraiu P sem apresentar relação com o tamponamento; do mesmo modo, o Bray-1, apesar de ter apresentado valores elevados de extração nos solos PAdx e PAd (Tabela 5), não se percebe relação com o poder tampão de fosfato dos solos.

Os solos LAd, PAd e GXve apresentaram alta CMAP e baixo P-rem; portanto, elevado poder tampão de fosfato, condizente com suas mineralogias (Figura 1 e Tabela 3) que mostraram a presença de gibsita, enquanto este mineral não foi encontrado no PAdx nem no EKo, solos com menor CMAP e maior P-rem, porém Bahia Filho et al. (1983), estudando solos do Brasil Central, consideraram a goethita principal componente da fração argila responsável pela adsorção de $\mathrm{P}$ e não a gibsita.

Neste trabalho se registrou a presença de goethita em todos os solos, com exceção do GXve, que só apresentou gibsita em sua composição mineralógica, porém foi o solo com a maior CMAP (Tabela 2). 
A partir do $\mathrm{P}$ extraído em função das doses aplicadas, ajustou-se modelo linear nos cinco solos estudados e as equações de regressão indicaram que as maiores taxas de recuperação foram encontradas quando o extrator de P foi a RTI (Figura 2).

Analisando as taxas de recuperação, percebe-se que Bray-1 apresentou maior extração de P para o EKo $(19,4 \%)$, seguido do PAd (14,0\%), PAdx (13,5\%), GXve (6,2\%) e LAd (3,4\%). A taxa de extração para Mehlich-1 mostrou que no EKo foi da ordem de $31,9 \%$, seguida do PAdx $(8,9 \%)$, PAd $(8,8 \%)$, GXve $(8,2 \%)$ e o LAd $(6,4 \%)$. Para Mehlich-3 foi maior para o PAd (13,6\%), seguida do EKo (11,4\%), PAdx (4,4\%), GXve $(3,6 \%)$ e o LAd $(2,0 \%)$. Para RTI verificou-se que a maior taxa de extração de P ocorreu no PAd $(95,0 \%)$, seguida do GXve $(68,5 \%)$, LAd $(41,8 \%)$, PAdx $(41,3 \%)$ e EKo $(32,9 \%)$ (Figura 2).

O EKo apresentou baixa CMAP e elevado P-rem (Tabela 2), tendo apresentado taxas de recuperação pelos extratores, na seguinte ordem: RTI, Mehlich-1, Bray-1 e Mehlich-3. A taxa de extração da RTI no EKo, quando comparada com a dos solos, foi a menor; no entanto, entre os extratores, especificamente para este solo, foi a que mais extraiu P, coerente com sua capacidade de esgotar o reservatório lábil de $\mathrm{P}$ dos solos (Silva \& Raij, 1999).

Também coerente com sua sensibilidade à capacidade tampão de $\mathrm{P}$ dos solos, o Melhich-1 extraiu muito $\mathrm{P}$ nesse solo, chegando a uma taxa de extração semelhante à da RTI (Figura 2), ou seja, em solos de menor tamponamento o Mehlich-1 parece, também, esgotar o reservatório lábil de $\mathrm{P}$, assim como a RTI.

Alguns pesquisadores (Rolim Neto et al., 2004; Silva et al., 2004; Rocha et al., 2005) obtiveram menores extrações de P com o aumento do poder tampão de fosfatos do solo evidenciando que solos com menor teor de argila, elevado valor de P-rem e baixa CMAP, devem apresentar as maiores extrações do P aplicado, como foi o caso dos EKo e PAdx (Figura 2).

A taxa de extração variou entre os solos, evidenciando que características químicas e físicas inerentes a cada solo, afetam o poder de recuperação dos extratores; coerentemente, as características químicas dos extratores também foram responsáveis pelas taxas de extração diferenciadas.

Cada extrator pode estar atuando de maneira a retirar $\mathrm{P}$ do solo de compartimentos diferentes ou, ainda, esses mesmos extratores podem ligar-se, quimicamente, a diferentes compostos. Resultados semelhantes foram encontrados por Silva et al. (2004).

Em todos os solos, o Mehlich-3 foi o que apresentou a menor taxa de extração, resultado que se assemelha aos encontrados por Valladares et al. (2001) que, comparando os teores de nutrientes extraídos por três métodos em solos do Rio de Janeiro, observaram que o Mehlich-3 subestimou as quantidades extraídas de $\mathrm{P}$.

Um fator a se considerar quando se analisa a taxa de recuperação dos extratores, é a fonte utilizada na adubação. $\mathrm{O}$ superfosfato triplo, apesar de baixos teores, tem $\mathrm{Ca}$ na sua composição; tendo em vista a quantidade aplicada do produto e o fornecido pela calagem, além de, em alguns casos, os teores já contidos no solo poderem influenciar a recuperação
A

Bray-1

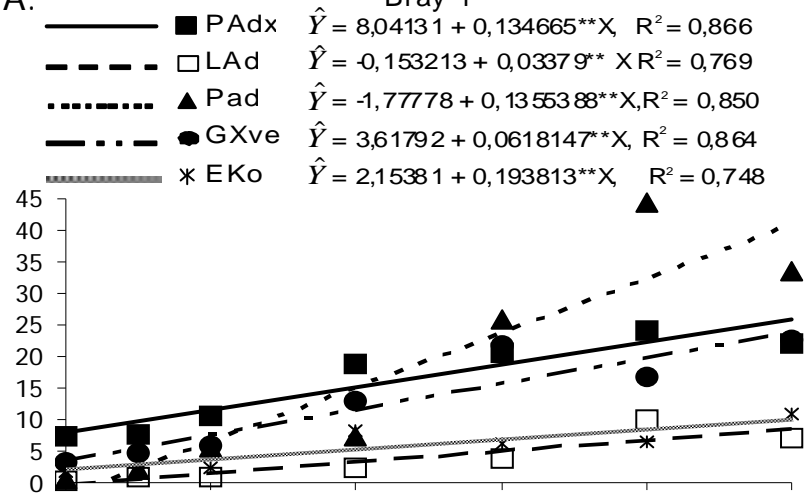

B.

Mehlich-1

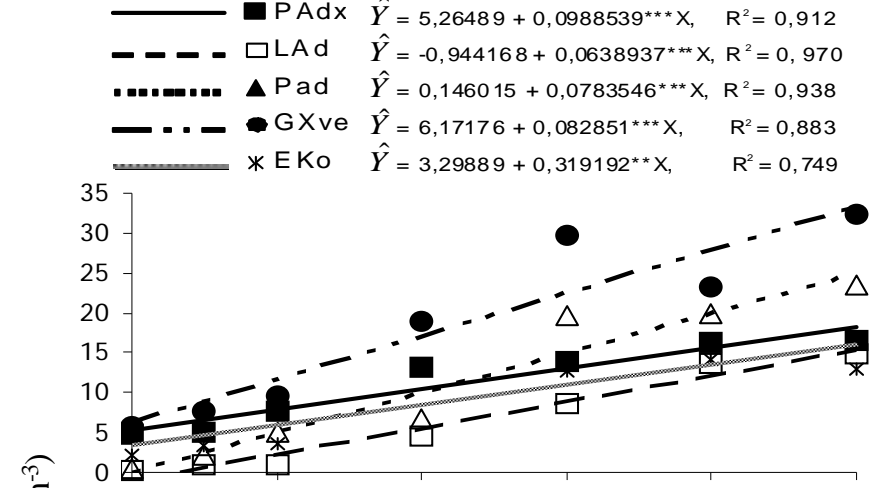

ह $\mathrm{E}$.

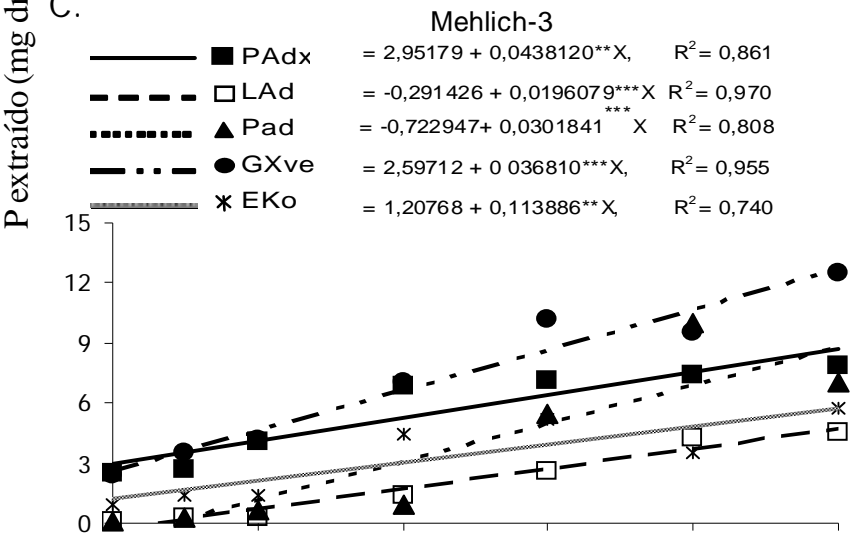

D.

RTI

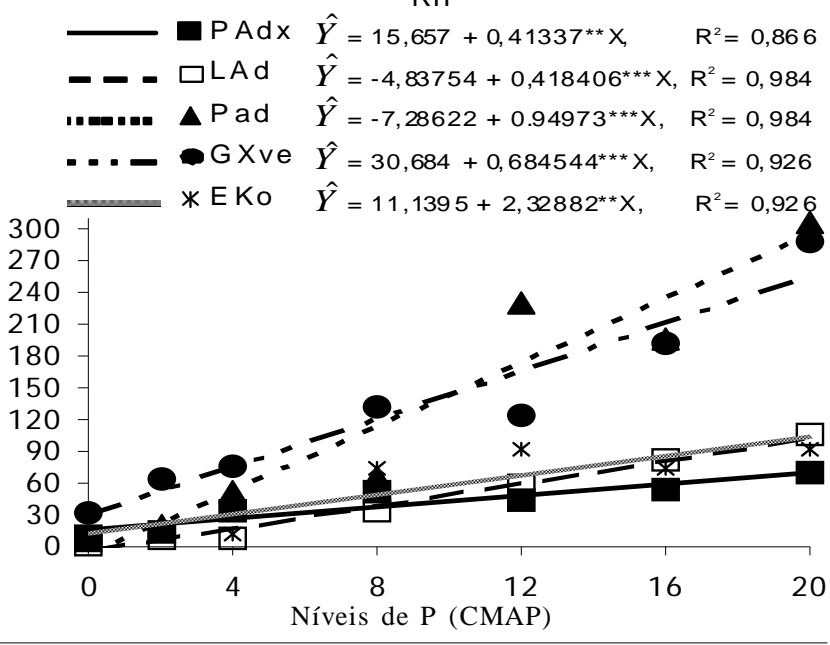

Figura 2. Equações de regressão que estimam o fósforo extraído pelos extratores Bray-1 (A), M ehlich-1 (B), Mehlich-3 (C) e Resina de Troca lônica (RTI) (D) em função do fósforo aplicado 
de $\mathrm{P}$ pelos extratores, principalmente quando a determinação do P extraído é realizada 30 dias após a aplicação das doses, o P ligado ao $\mathrm{Ca}$ (P-Ca) faria com que o poder de recuperação do Mehlich-3 fosse diminuído e o do Mehlich-1 aumentado justificando, provavelmente, a maior taxa de recuperação do segundo extrator em relação ao primeiro, em todos os solos.

A forma de ligação do P com os demais elementos no solo pode afetar a ação dos extratores. Rocha et al. (2005), estudando solos de Fernando de Noronha encontraram correlação significativa do P extraído por Mehlich-1 com P-Ca e do Mehlich-3 com P ligado a Fe (P-Fe).

Os extratores se comportaram de maneira distinta, em que a RTI apresentou a maior taxa de recuperação e o Mehlich-3, a menor, demonstrando que nos solos utilizados existe tendência de extração de P diferenciada entre os compartimentos; no entanto, a RTI foi o extrator que apresentou comportamento mais estável no conjunto dos solos, corroborando com o trabalho de Silva \& Raij (1999), ao concluírem que a RTI apresentou o melhor coeficiente de determinação nos mais variados tipos de solo.

Características químicas e físicas dos solos foram correlacionadas com a taxa de recuperação dos extratores (Tabela 6). Para Mehlich-1, o maior grau de significância da taxa de recuperação foi verificada com a CMAP sendo, ainda, significativo para Argila e P-rem, indicativo da influência do poder tampão de fosfato do solo no teor de $\mathrm{P}$ extraído pelo extrator. O Mehlich-3 também apresentou coeficientes de determinação maiores e grau de significância maior para CMAP, enquanto o Mehlichi-1 mostrou correlação significativa e positiva com o P-rem indicando que, quanto maior for o P-rem de um solo, maior também será o poder de extração. As correlações significativas e negativas com a CMAP e argila indicaram que, quanto maior o valor dessas características maior, sem dúvida, será o poder tampão do solo e menor a capacidade de extração.

Tabela 6. Coeficiente de correlação linear simples entre a taxa de fósforo extraída por Bray-1, Mehlich-1, Mehlich-3 e Resina de Troca Aniônica (RTI) e características químicas e físicas dos solos

\begin{tabular}{ccccc}
\hline \multirow{2}{*}{ Características } & \multicolumn{4}{c}{ Extrator } \\
\cline { 2 - 5 } Argila & Bray-1 & Mehlich-1 & Melich-3 & RTI \\
P-rem & $-0,9102^{*}$ & $-0,7062^{\circ}$ & $-0,7692^{\circ}$ & $-0,5824^{\text {ns }}$ \\
CMAP & $0,8261^{*}$ & $0,7643^{\circ}$ & $0,8270^{*}$ & $0,5874^{\text {ns }}$ \\
Feo & $-0,7419^{\circ}$ & $-0,8272^{*}$ & $-0,8612^{*}$ & $-0,6398^{\text {ns }}$ \\
Fed & $-0,5985^{\text {ns }}$ & $-0,7108^{\circ}$ & $-0,7609^{\circ}$ & $-0,4715^{\text {ns }}$ \\
\hline
\end{tabular}

$* \mathrm{e}^{\circ}$ significativo a 5 e $10 \%$ de probabilidade, respectivamente. ${ }^{\text {ns }}$ não significativo

As maiores correlações para Bray-1 da taxa de recuperação ocorreram com argila, seguidas de P-rem e CMAP, não sendo significativo para Feo e Fed mostrando, também, influência do poder tampão de fosfato no poder de extração.

A RTI não mostrou correlação significativa da taxa de recuperação para nenhuma das características consideradas, indicando que não é influenciada pelo poder tampão do solo e que não sofre influência das características químicas e físicas dos solos estudados.

Os extratores Bray-1, Mehlich-1, Mehlich-3 e a RTI não apresentaram correlação significativa para o Fed, sinal de que, para os solos estudados, esta característica exerceu pouca influência sobre o poder de recuperação dos extratores, cujos resultados evidenciaram a sensibilidade dos extratores Bray-1, Mehlich-1 e Mehlich-3, as características dos solos, a qualidade dos argilominerais e, ainda, a sua superfície específica, por apresentarem correlação com o poder tampão de fosfato do solo e, consequentemente, afetarem o poder de recuperação dos extratores.

Segundo Rolim Neto et al. (2004), nos Latossolos estudados em seu experimento, com texturas e materiais de origem variável, a proporção e a área superficial da gibsita e goethita tiveram participação destacada na adsorção de P.

Valladares et al. (2003) encontraram correlação da CMAP e do teor de argila, ou seja, duas características que aumentam o poder tampão de fosfato dos solos e, consequentemente, afetam o poder de extração de determinados extratores. Silva et al. (2004) demonstraram a influência da argila na adsorção de P; desta forma, os extratores Mehlich-1, Mehlich-3 e Bray-1 se correlacionaram com ambas as características, evidenciando a sua importância na taxa de recuperação dos extratores, que poderá ser fundamental na sua capacidade em predizer a disponibilidade de P; por outro lado, a RTI não apresentou correlação significativa em nenhuma das características avaliadas, corroborando com o trabalho realizado por Silva \& Raij (1999), que descreveram a RTI como sendo o melhor extrator para os mais variados tipos de solo.

Segundo Raij et al. (1984), um dos inconvenientes da RTI na extração de P é o fato de ser um método trabalhoso; contudo, pode-se aferir que a RTI não tem seu poder de recuperação modificado ou afetado com a presença no solo de características que elevem a CMAP e, assim, não subestima o $\mathrm{P}$ lábil. Alguns pesquisadores (Loganathan \& Fernando, 1980; Motomiya et al., 2004; Corrêa et al., 2008) mostraram que quando se aplica uma fonte solúvel de $\mathrm{P}$, frequentemente grande parte do aplicado é adsorvida rapidamente. Segundo Gonçalves et al. (1985) a velocidade de adsorção é maior em solos com maior CMAP e, quanto maior a saturação dos sítios de adsorção menor a velocidade de transformação de fósforo lábil em $\mathrm{P}$ não lábil.

Como a RTI atua no P lábil (Silva \& Raij, 1999), isto pode explicar a eficiência da RTI, mesmo em solos com maior CMAP, visto que a amostragem dos solos para determinação da capacidade de recuperação de $\mathrm{P}$ dos extratores ocorreu aos 30 dias após a aplicação dos tratamentos.

\section{CONCLUSÕES}

1. O Mehlich-1 foi o extrator que melhor se correlacionou com as características dos solos que refletem o poder tampão de fosfato.

2. A RTI não apresentou correlação com nenhuma característica química ou física dos solos que refletem o poder tampão de fosfato. 
3. O extrator Mehlich-3 correlacionou-se com a CMAP, porém extraiu menos $\mathrm{P}$ que o Mehlich-1, em todos os solos, e o Bray-1 extraiu menos P na maioria dos solos estudados.

\section{AGRADECIMENTOS}

À Diretoria e gerência agrícola das unidades agroindustriais em que foram conduzidos os experimentos: Usina Cucau, Usina Pumaty, Usina Salgado e Usina Santa Teresa.

\section{LITERATURA CITADA}

Almeida, J. A.; Torrent, J.; Barrón, V. Cor de solo, formas do fósforo e adsorção de fosfatos em Latossolos desenvolvidos de basalto do extremo-sul do Brasil. Revista Brasileira da Ciência do Solo, v.27, p.985-1002, 2003.

Alvarez, V. V. H.; Fonseca, D. M. Definição de doses de fósforo para determinação da capacidade máxima de adsorção de fosfatos e para ensaios em casa de vegetação. Revista Brasileira da Ciência do Solo, v.14, n.1, p.44-55, 1990.

Alvarez, V. V. H.; Novais, R. F.; Dias, L. E.; Oliveira, J. A. Determinação e uso do fósforo remanescente. Viçosa: Sociedade Brasileira de Ciência do Solo, 2000. p.27-33. Boletim Informativo, 25

Bahia Filho, A. F. C.; Braga, J. M.; Resende, M.; Ribeiro, A. C. Relação entre adsorção de fósforo e componentes mineralógi$\cos$ da fração argila de Latossolos do planalto central. Revista Brasileira de Ciência do Solo, v.7, p.221-226, 1983.

Bastos, A. L.; Costa, J. P. V.; Silva, I. F.; Raposo, R. W. C.; Souto, J. S. Influência de doses de fósforo no fluxo difusivo em solos de Alagoas. Revista Brasileira de Engenharia Agrícola e Ambiental, v.12, n.2, p.136-142, 2008.

Braga, J. M.; Defelipo, B. V. Determinação espectrofotométrica de fósforo em extrato de solo e material vegetal. Revista Ceres, v.21, p.73-85, 1974.

Bray, R. H.; Kurtz, L. T. Determination of total, organic and available forms of phosphorus in soils. Soil Science, v.59, p.3945, 1945.

Corrêa, R. M.; Nascimento, C. W. A.; Freire, F. J.; Souza, S. K. S. C.; Ferraz, G. B. Disponibilidade e níveis críticos de fósforo em milho e solos fertilizados com fontes fosfatadas. Revista Brasileira de Ciências Agrárias, v.3, p.218-224, 2008.

Corrêa, R. M.; Nascimento, C. W. A.; Souza, S. K. S. C.; Freire, F. J.; Ferraz, G. B. Gafsa rock phosphate and the triple superphosphate for dry matter production and $\mathrm{P}$ uptakeby corn. Scientia Agrícola, v.62, n.2, p.159-164, 2005.

EMBRAPA - Empresa Brasileira de Pesquisa Agropecuária. Manual de métodos de análises de solo. 2.ed. Rio de Janeiro: MAB, 1997. 212p.

Gonçalves, J. L. M.; Firme, D. J.; Novais, R. F.; Ribeiro, A. C. Cinética de adsorção de fósforo em solos de cerrado. Revista Brasileira de Ciência do Solo, v.9, p.107-111, 1985.

IBGE - Instituto Brasileiro de Geografia e Estatística. Sidra 97: Sistema IBGE de Recuperação automática. Rio de Janeiro, 2007. <http://www.ibge.gov.br>. 28 Dez. 2007.
IPA - Instituto de Pesquisa Agropecúaria de Pernambuco. Recomendações de adubação para o estado de Pernambuco ( $2^{\mathrm{a}}$ aproximação). 2.ed. Recife: IPA, 1998. 198p.

Koffler, N. F.; Lima, J. F. W. F.; Lacerda, M. F.; Santana, J. F.; Silva, M. A. (ed.). Caracterização edafo-climática das regiões canavieiras do Brasil: Pernambuco. Piracicaba: IAA/Planalsucar, 1986. 78p.

Loganathan, P.; Fernando, W. T. Phosphorus sorption by some coconut-growingacid soil of Srilanka and is relationship to selected soil propertirs. Journal of Science Food Agriculture, v.31, p.709-717, 1980.

Mehlich, A. New extractant for soil test evaluation of phosphorus, potassium, magnesium, calcium, sodium, manganese and zinc. Communication in Soil Science and Plant Analysis, v.9, p.477-492, 1978.

Mehlich, A. Mehlich-3 soil test extractant: a modification of Mehlich-2 extractant. Communication in Soil Science and Plant Analysis, v.15, p.1409-1416, 1984.

Mehra, O. P.; Jackson, M. L. Iron oxide removal from clays by dithionite - citrate - bicarbonate system buffered with sodium bicarbonate. Clays and Clay Minerals, v.7, p.317-327, 1960.

Motomiya, W. R.; Fabrício, A. C.; Marchetti, M. E.; Gonçalves, M. C.; Robaina, A. D.; Novelino, J. O. Métodos de aplicação de fosfato na soja em plantio direto. Pesquisa Agropecuária Brasileira, v.39, p.307-312, 2004.

Raij, B. van; Andrade, J. C.; Cantarella, H.; Quaggio, J. A. Análise química para avaliação da fertilidade de solos tropicais. Campinas: Instituto Agronômico, 2001. 284p.

Raij, B. van; Feitosa, C. T.; Silva, N. M. da. Comparação de quatro extratores de fósforo de solos. Bragantia, v.43, n.1, p.1729, 1984.

Raij, B. van; Quaggio, J. A.; Silva, N. M. Extraction of phosphorus, potassium, calcium, and magnesium from soils by an ionexchange resin procedure. Communication in Soil Science and Plant Analysis, v.17, p.547-566, 1986.

Rocha, A. T.; Duda, G. P.; Nascimento, C. W. A.; Ribeiro, M. R. Fracionamento de fósforo e avaliação de extratores de P-disponível em solos da ilha de Fernando de Noronha. Revista Brasileira de Engenharia Agrícola e Ambiental, v.9, n.2, p.178184, 2005.

Rolim Neto, F. C.; Schaefer, C. E. G. R.; Costa, L. M.; Corrêa, M. M.; Fernandes Filho, E. I.; Ibraimo, M. M. Adsorção de fósforo, superfície específica e atributos mineralógicos em solos desenvolvidos de rochas vulcânicas do Alto Paranaíba-MG. Revista Brasileira de Ciência do Solo, v.28, p.953-964, 2004.

Rossi, C.; Fagundes, J. L. Determinação do teor de fósforo em solos por diferentes extratores. Revista de Agricultura, v.73, n.2, p.215-227, 1998.

Schwertmann, U. The differentiation of iron oxides in soils by a photochemical extraction with acid ammonium oxalate. Zeitschrift fuer Pflanzenernaehrung und Bodenkunde, v.105, p.194201, 1964

Silva, E. M. B.; Freire, F. J.; Santos, M. V. F.; Silva, T. J. A.; Freire, M. B. G. S. Níveis críticos de fósforo para Brachiaria brizantha e suas relações com características físicas e químicas em solos de Pernambuco. Revista Brasileira da Ciência do Solo, v.28, p.281-288, 2004. 
Silva, F. C.; Raij, B. van. Disponibilidade de fósforo em solos avaliada por diferentes extratores. Pesquisa Agropecuária Brasileira, v.34, n.2, p.267-288, 1999.

Silveira, M. M. L.; Araújo, M. S. B.; Sampaio, E. V. S. B. Distribuição de fósforo em diferentes ordens de solo do semi-árido da Paraíba e de Pernambuco. Revista Brasileira de Ciência do Solo, v.30, p.281-291, 2006.

Valladares, G. S.; Pereira, M. G.; Anjos, L. H. C. Adsorção de fósforo em solos de argila de atividade baixa. Bragantia, v.62, n.1, p.111-118, 2003.
Valladares, G. S.; Pereira, M. G.; Souza, J. M. P. F.; Pérez, D. V.; Anjos, L. H. C. Comparação entre os teores de nutrientes extraídos por três métodos em amostras de solos do Rio de Janeiro. Revista Brasileira de Agrociência, v.7 n.2, p.137-141, 2001.

Whitting, L. D.; Allardice, W. R. X-ray diffraction techniques. In: Klute, A. (ed.). Methods of soil analysis. Part. 1 Physical and mineralogical methods. Madison: SSSA, 1986. cap.9, p.331359. 